\title{
ANALISIS PERBANDINGAN METODE FILTER MEAN, MEDIAN, MAXIMUM, MINIMUM, DAN GAUSSIAN TERHADAP REDUKSI NOISE GAUSSIAN, SALT\&PAPPER, SPECKLE, POISSON, DAN LOCALVAR
}

\author{
I Gede Aris Gunadi ${ }^{1}$, Putu Satya Saputra ${ }^{2}$, Putu Aditya Pratama ${ }^{3}$, I Putu Adhy Wicaksana Indra \\ Saputra ${ }^{4}$ \\ 1) Jurusan Pendidikan Fisika FMIPA / Prodi S2 Ilmu Komputer Universitas Pendidikan Ganesha \\ 2,3,4) Prodi S2 Ilmu Komputer Universitas Pendidikan Ganesha \\ 1) igedearisgunadi@undiksha.ac.id
}

\begin{abstract}
Due to the influence of noise on an image, the image will experience a decrease in quality. If the type of noise is known for certain, then the right solution can be determined to restore the condition of an image so that the condition returns to normal. The effort to restore the image condition is stated by image restoration. The most important thing in image restoration is determining the type of noise and the solution for the noise.

In this study several types of noise were tried, gaussian, salt \& paper, speckle, poisson, and Localvar on several image samples. In the image that had been exposed to noise, repairs were carried out with several types of filters including gaussian, mean, median, maximum, and minimum. Next was the quality of noise reduction with each filter determined based on the value of PSNR and MSE. The results of image restoration experiments showed that the mean filter was the best filter used to improve noisegaussian, salt \& peppers and speckle image quality. The median filter is the filter that is best used to improve image quality with poisson and localvar noise types.
\end{abstract}

Keywords : Image Restoration, Filtering, Noise, PSNR, MSE

\section{PENDAHULUAN}

Pengolahan citra digital (digital image processing) adalah sebuah disiplin ilmu yang mempelajari tentang teknik-teknik mengolah citra (Patidar, Gupta, Srivastava, \& Nagawat, 2010), (Dewi \& Gunadi, 2018), (Kusumanto, Tompunu, \& Pambudi, 2011). Terdapat beberapa proses teknik pengolahan citra yaitu image enhancement, image segmentation, image analysis, image restoration, image compression dan image reconstruction. Restorasi citra merupakan proses merekonstruksi (reconstruct) atau mendapatkan kembali (recover) suatu citra yang telah mengalami penurunan kualitas (degraded) (Wedianto, Sari, \& H, 2016). Beberapa contoh kerusakan yang bisa di restorasi seperti bintik-bintik, dual image, over saturated color, dan pixel error. Kerusakan akan tampak pada citra yang diterima bergantung pada gangguan yang terjadi. Biasanya dapat diketahui tipe kerusakan yang mungkin muncul. Dengan demikian tipe derau juga dapat diketahui yang selanjutnya dapat dipilih metode yang paling cocok untuk mengurangi efek derau yang ditimbulkan.

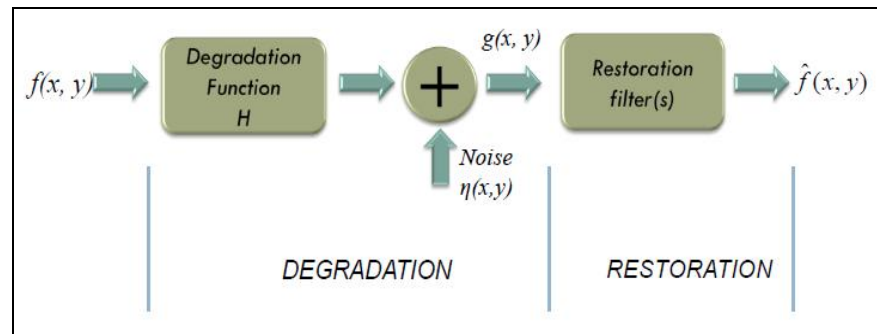

Gambar 1. Proses restorasi citra 
Gambar 1. merupakan citra input $\mathrm{f}(\mathrm{x}, \mathrm{y})$ yang mengalami degradasi noise $\mathrm{n}(\mathrm{x}, \mathrm{y})$. Tujuan dari restorasi adalah mendapatkan kembali prakiraan $\mathrm{f}^{\prime}(\mathrm{x}, \mathrm{y})$, dari citra asli (awal) dengan adanya beberapa konstanta yang dimiliki seperti $\mathrm{g}(\mathrm{x}, \mathrm{y})$, fungsi degradasi $\mathrm{H}$, dan fungsi noise $\mathrm{n}(\mathrm{x}, \mathrm{y})$. Penelitian ini akan membahas restorasi citra dengan berbagai filter yaitu filter median, mean, maximum, minimum, dan gaussian. Citra tersebut akan diberikan 5 noise yang berbeda terlebih dahulu yaitu gaussian, salt \& pepper, speckle, poisson dan localvar noise. Hasil filter masing - masing berupa kernel 3x3, 5x5 dan 7x7 kemudian dihitung nilai MSE dan PSNR. Tujuan penelitian ini untuk menganalisa filter yang sesuai digunakan untuk setiap noise.

\section{TINJAUAN PUSTAKA}

\subsection{Noise}

Noise merupakan kesalahan yang terjadi dalam proses pengambilan citra yang menyebabkan sebuah nilai intensitas piksel tidak mencerminkan nilai intensitas piksel yang sebenarnya (Rohit Verma \& Ali, 2013). Intensitas warna dari noise bernilai antara 0 sampai 255 (Rachmad, 2008). Gambar 2. merupakan citra yang terkorupsi oleh noise gaussian, salt\& pepper, poisson, speckle.

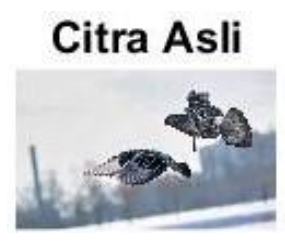

(c)

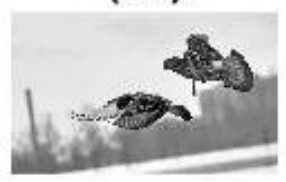

( a )

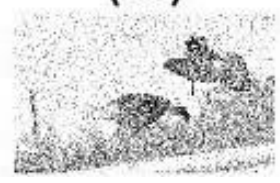

(d)

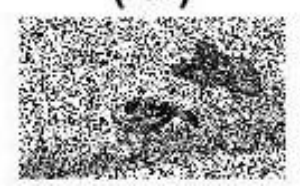

(b)

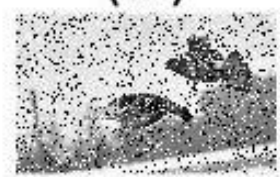

(e)

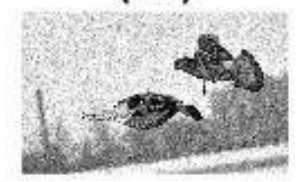

Gambar 2. (a) Gaussian, (b) Salt \& Pepper, (c) Poisson, (d) Speckle, (e) Localvar

a. Gaussian noise merupakan model noise yg mengikuti distribusi normal standard dengan rata-rata nol dan standard deviasi 1 . Efek dari noise ini adalah munculnya titiktitik berwarna yang jumlahnya sama dengan prosentase noise.

b. Salt and pepper noise jenis ini terlihat seperti bintik garam dan merica. Pada citra akan nampak seperti titik-titik. Untuk citra RGB titik-titik muncul dalam tiga warna yakni merah (red), hijau (green) dan biru (blue), sedangkan pada citra GRAY noise akan muncul dalam dua warna yakni hitam (black) dan putih (white). Noise ini memberikan efek "on dan off" pada pixel.

c. Poisson noise bukan merupakan noise buatan. Poisson merupakan noise yang ditambahkan langsung pada citra tanpa menambahkan parameter apapun, sehingga efeknya pada citra pun tetap, berbeda dengan tipe noise lainnya.

d. Speckle merupakan noise ganda. Noise ini ditambahkan pada citra menggunakan persamaan $\mathrm{J}=\mathrm{I}+\mathrm{n}^{*} \mathrm{I}$, dimana $\mathrm{n}$ terdistribusi random seragam dengan mean 0 dan variance V. V adalah konstanta non negative yang besarnya dapat berubah-ubah. 
Default nilai untuk V adalah 0.04. Makin besar nilai V maka citra akan semakiin kabur.

e. Localvar merupakan gaussian noise dengan mean 0, dengan variance noise adalah fungsi dari intensitas citra yang nilainya berada dalam matrik citra. Vektor intensitas citra tidak boleh bernilai sama karena citra akan nampak sebagai layar putih (Gaussian White Noise). Vektor intensitas citra harus bernilai antara 0 dan 1 (normal)

\subsection{Filter Image}

Filter image adalah sebuah metode untuk meredamkan atau menghilangkan noise pada citra digital atau image(Yuwono, 2010). Jenis filter bermacam-macam dan fungsi serta efeknya juga berbeda-beda. Filter citra dibagi menjadi dua, yaitu filter linear dan filter non-linear (Putra, 2010). Filter spasial linear adalah filter yang bekerja dengan cara korelasi atau konvolusi. Filter spasial non-linier atau biasanya disebut juga dengan filter statistik berdasar urutan adalah filter yang respon nya didasarkan pada urutan atau rangking piksel yang ada dalam citra yang dicakup oleh area filter dengan menggantikan nilai dari piksel yang berada di tengah digantikan dengan nilai hasil pengurutan atau perangkingan tersebut. Beberapa jenis filter yang umum digunakan adalah:

a. Filter Spasial Non Linear

Beberapa jenis filter spasial non linear yang umum digunakan adalah filter maksimum, minimum, dan median. Mekanisme filter spasial non linear didasarkan pada pengurutan intensitas piksel piksel tetangga yang dikenakan filter pada saat proses konvulusi. Ilustrasi Pada Gambar 3 menunjukan kerja filter spasial non linear.

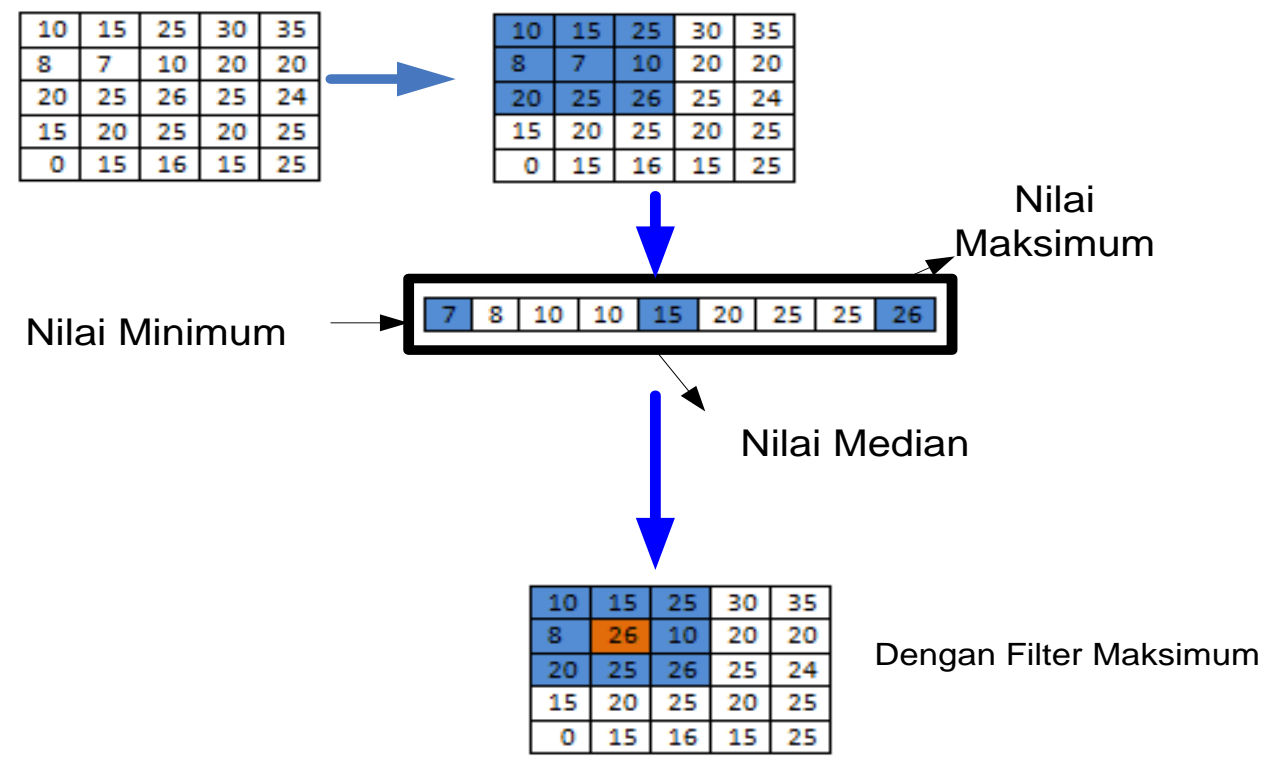

Gambar 3. Ilustrasi mekanisme filter non linear

Pada Gambar 3 ditunjukan mekanisme proses konvolusi pada proses filtering dengan menggunakan filter non spasial linear. Pada Gambar 3 ditunjukan dengan filter maksimum, sedangkan jika menggunakan filter median, ataupun filter minimum maka 
nilai tengah area window filter setiap tahap proses konvulusi diganti dengan dengan nilai median, atau nilai minimum.

b. Filter Mean

Filter mean atau aritmatic mean filter adalah menghitung rata -rata nilai pixel pada setiap tahap proses konvolusi. Nilai rata rata tersebut digunakan untuk menganti nilai pixel pada pusat window pada proses konvolusi. Ilustrasi ditunjukan Gambar 4.

\begin{tabular}{|l|l|l|l|l|}
\hline 10 & 15 & 25 & 30 & 35 \\
\hline 8 & 7 & 10 & 20 & 20 \\
\hline 20 & 25 & 26 & 25 & 24 \\
\hline 15 & 20 & 25 & 20 & 25 \\
\hline 0 & 15 & 16 & 15 & 25 \\
\hline
\end{tabular} \mid \begin{tabular}{|l|l|l|l|l|}
\hline 10 & 15 & 25 & 30 & 35 \\
\hline 8 & 7 & 10 & 20 & 20 \\
\hline 20 & 25 & 26 & 25 & 24 \\
\hline 15 & 20 & 25 & 20 & 25 \\
\hline 0 & 15 & 16 & 15 & 25 \\
\hline
\end{tabular}

\section{$1 / 9^{4}(7+8+10+10+15+20+25+25+26)=16.2=16$}

Gambar 4. Mekanisme filter mean

c. Filter Gaussian

Filter gaussian dilakukan dengan menganti setiap pixel dengan sebuah nilai yang didasarkan pada rata rata dari proses pembobotan pixel tersebut dan seluruh tetangganya. Jumlah pixel tetangga yang dilibatkan tergantung pada filter yang dirancang. Umumnya digunakan dua variabel, disebut dengan Zero mean gaussian, dinyatakan dengan Persamaan 1 (Sutoyo, Mulyanto, Suhartono, Nurhayati, \& Wijanarto, 2009).

$$
g(x, y)=e^{-\frac{x^{2}+y^{2}}{2 \mathscr{\delta}^{2}}}
$$

\subsection{Mean Square Error (MSE)}

Mean Square Error (MSE) adalah nilai error kuadrat rata-rata antara citra asli dengan citra manipulasi. MSE digunakan untuk menghitung beda (kesalahan) antara citra masukan dan citra keluaran (Wang \& Li, 2011).

$$
M S E=\frac{1}{M N} \sum_{X=1}^{M} \sum_{Y=1}^{N}\left(S_{x y}-C_{x y}\right)^{2}
$$

Dimana $\mathrm{x}$ dan y adalah koordinat dari gambar, $\mathrm{M}$ dan $\mathrm{N}$ adalah dimensi dari gambar, $\mathrm{S} \_\mathrm{xy}$ menyatakan stego-image dan C_xy menyatakan cover-image. C_max ${ }^{\wedge} 2$ memiliki nilai maksimum dalam gambar yaitu nilai maksimum dari nilai piksel adalah 255 dan minimum adalah 1 


\subsection{Peak Signal to Noise Ratio (PSNR)}

PSNR adalah menyatakan perbandingan kualitas citra sebelum dikenai perlakuan tertentu dengan kualitas citra setelah dikenai perlakukan. PSNR dinyatakan dalam persamaan 3. Kualitas perlakuan seperti pemilteran dapat dilihat dengan menganalisis nilai PSNR. Terkait dengan pengaruh filter, nilai PSNR yang rendah menunjukan filter yang diaplikasikan pada sebuah citra memiliki pengaruh positif pada proses reduksi noise.

$$
P S N R=10 \log _{10}\left(\frac{C_{\max }^{\mathrm{x}}}{M S E}\right)
$$

\section{METODE PENELITIAN}

Metode penelitian yang digunakan dalam penelitian ini menggunakan metode kuantitatif eksperimen dengan menguji berbagai filter citra sebagai variabel yang telah direduksi noise.

\subsection{Teknik Analisa Data}

Berikut merupakan tahapan yang dilakukan dari proses input citra, menambahkan noise pada citra, perbaikan citra dengan berbagai filter, mencari nilai rata - rata MSE dan PSNR.

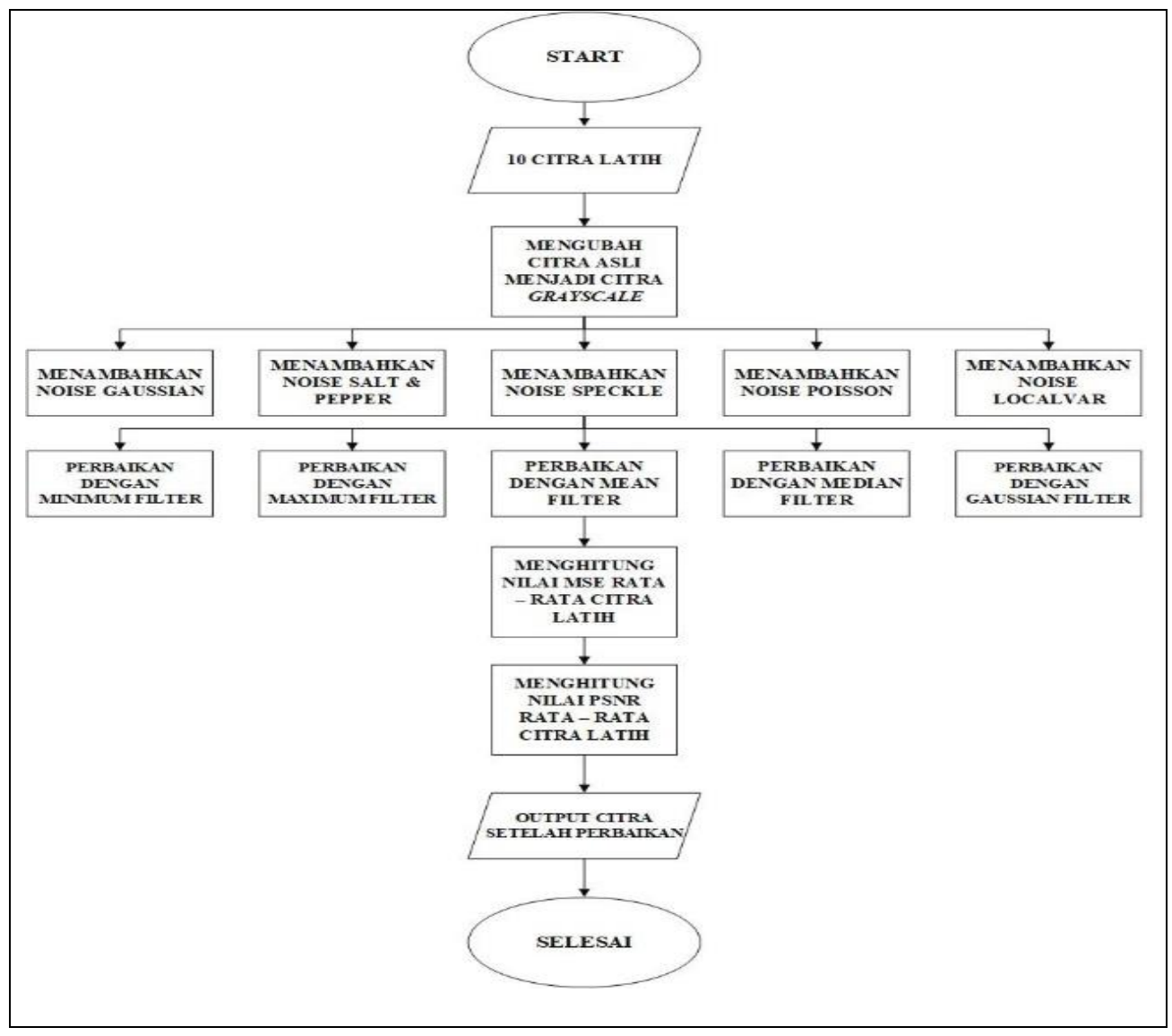

Gambar 3. Flowchart tahapan perbaikan citra 
Pada penelitian ini digunakan 10 sampel citra yang berbeda, dan format citra dinyatakan dalam bentuk gray citra. Pada masing-masing citra tersebut ditambahkan noise gaussian, salt \& pepper, poisson, speckle dan localvar pada citra grayscale. Proses filtering dengan filter maximum, minimum, median, mean dan gaussian dengan menggunakan ukuran filter $3 \times 3,5 \times 5,7 \times 7$ untuk perbaikan kualitas citra. Pengaruh proses filtering dianalisis dengan mencari nilai MSE dan PSNR.

\section{HASIL DAN PEMBAHASAN}

Restorasi citra yang direduksi oleh beberapa noise dilakukan dengan aplikasi Matlab R2016a. Citra yang digunakan dalam perbaikan citra bernoise ini berfomat *.jpg dan terbatas hanya pada citra grayscale.

\subsection{Proses Penambahan Noise}

Gambar 4 menunjukan penambahan berbagai macam noise yang digunakan pada penelitian ini pada sebuah citra.
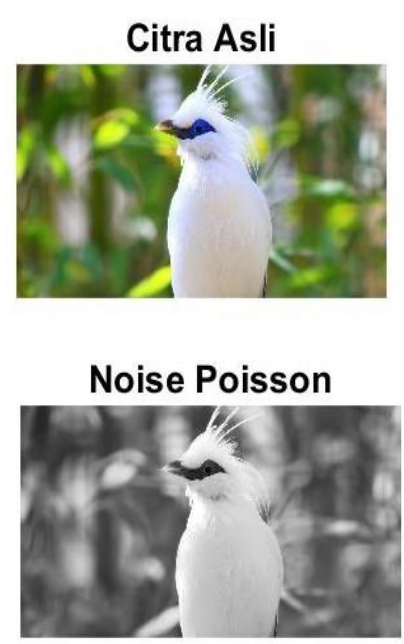
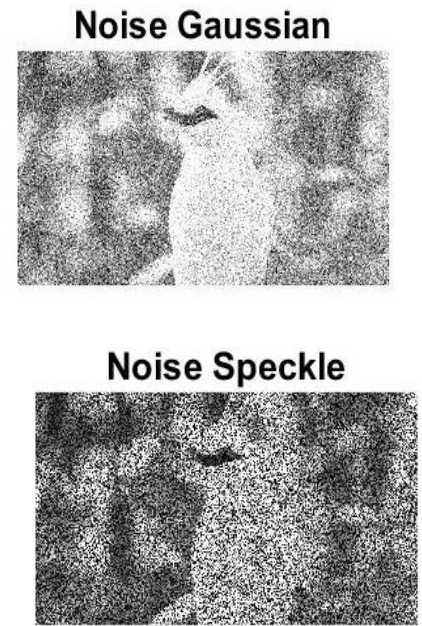
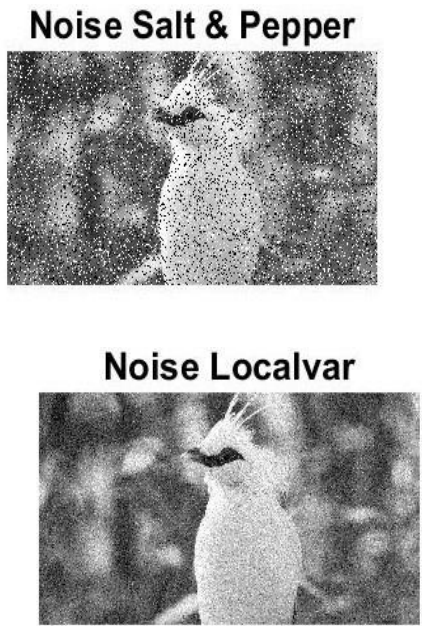

Gambar 4. Citra grayscale dengan noise

Gaussian, salt \& pepper, poisson, speckle dan localvar

Gambar 4. menunjukkan citra input diubah menjadi citra grayscale kemudian direduksi noise gaussian $(\mathrm{m}=0.2$, var $=0.05)$, salt \& pepper $(\mathrm{d}=0.2)$, poisson, speckle $(\mathrm{var}=0.5)$ dan localvar (intensity_map=0.02). Semakin besar nilai variance yang diberikan pada citra maka citra akan menjadi semakin ber-noise.

\subsection{Proses Filtering}

Proses filtering dengan berbagai macam filter yang digunakan pada penelitian ini ditunjukan pada Gambar 5. Secara keseluruhan Nilai MSE dan PSNR untuk berbagai filter dengan variasi ukuran ukuran filter 3x3, 5x5, dan 7x7, ditunjukan pada Tabel 1 . 

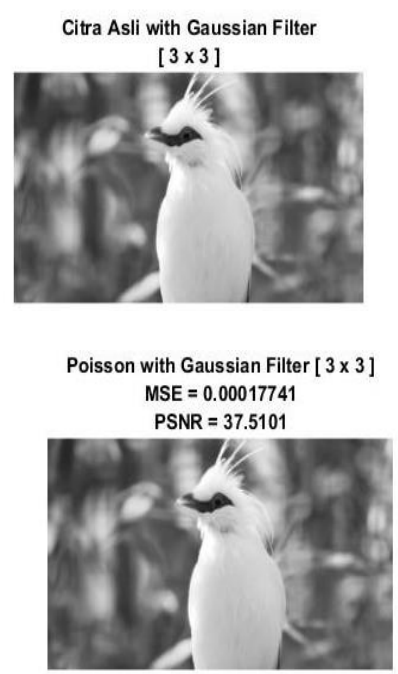
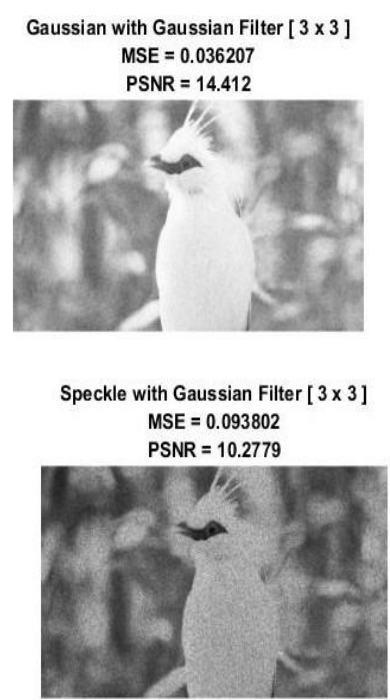

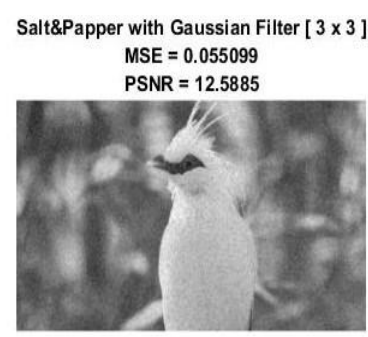

LocalVar with Gaussian Filter [ $3 \times 3$ ] MSE $=0.0095312$ MSE $=0.0095312$
PSNR $=20.2085$

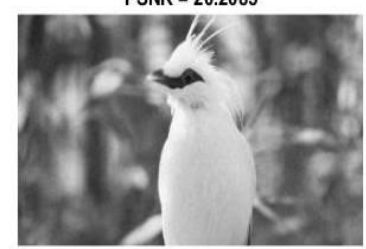

Gambar 5. Penerapan filter gaussian matriks 3x3

Tabel 1. Perhitungan nilai rata - rata MSE dan PSNR

\begin{tabular}{|c|c|c|c|c|c|c|c|}
\hline \multirow[t]{2}{*}{ Noise } & \multirow[t]{2}{*}{ Filter } & \multicolumn{3}{|c|}{ MSE } & \multicolumn{3}{|c|}{ PSNR } \\
\hline & & $3 \times 3$ & $5 \times 5$ & $7 \times 7$ & $3 \times 3$ & $5 \times 5$ & $7 \times 7$ \\
\hline \multirow{5}{*}{$\begin{array}{l}\text { Gaussian } \\
(\mathrm{m}=0.2, \\
\text { var }=0.05)\end{array}$} & Minimum & 0.1257853 & 0.1814897 & 0.254319 & 8.84413 & 7.00554 & 5.98188 \\
\hline & Maximum & 0.0842345 & 0.1586298 & 0.116294 & 11.04016 & 10.04562 & 9.68502 \\
\hline & Mean & 0.0286277 & 0.0318326 & 0.033426 & 15.59697 & 15.12615 & 14.9015 \\
\hline & Median & 0.030948 & 0.0521129 & 0.0338942 & 15.24943 & 14.98108 & 14.84055 \\
\hline & Gaussian & 0.0320383 & 0.0337965 & 0.0348731 & 15.11532 & 14.87542 & 14.72923 \\
\hline \multirow{5}{*}{$\begin{array}{l}\text { Salt \& } \\
\text { Papper } \\
(\mathrm{d}=0.2)\end{array}$} & Minimum & 0.261594 & 0.403336 & 0.411769 & 5.77441 & 4.12435 & 3.83406 \\
\hline & Maximum & 0.179639 & 0.259443 & 0.275487 & 7.53498 & 5.99479 & 5.74296 \\
\hline & Mean & 0.055141 & 0.0606063 & 0.0624334 & 12.6079 & 12.19776 & 12.06931 \\
\hline & Median & 0.0636114 & 0.0649622 & 0.0656586 & 11.99841 & 11.90665 & 11.8606 \\
\hline & Gaussian & 0.0612339 & 0.0631446 & 0.0646966 & 12.15119 & 12.01643 & 11.91377 \\
\hline \multirow{5}{*}{$\begin{array}{l}\text { Speckle } \\
\text { (var=0.5) }\end{array}$} & Minimum & 0.346748 & 0.402685 & 0.408341 & 4.68237 & 4.0428 & 3.98498 \\
\hline & Maximum & 0.250769 & 0.282466 & 0.296987 & 6.01512 & 5.50091 & 5.28718 \\
\hline & Mean & 0.0982564 & 0.1068404 & 0.1096671 & 10.11825 & 9.75378 & 9.63966 \\
\hline & Median & 0.1168606 & 0.1234536 & 0.1260049 & 9.39109 & 9.16466 & 9.0829 \\
\hline & Gaussian & 0.1084235 & 0.1112442 & 0.1129732 & 9.68672 & 9.57256 & 9.5058 \\
\hline \multirow{5}{*}{ Poisson } & Minimum & 0.009589 & 0.0205866 & 0.0315318 & 20.89032 & 17.52155 & 15.6884 \\
\hline & Maximum & 0.0056604 & 0.0128957 & 0.0197764 & 23.31633 & 19.59441 & 17.71303 \\
\hline & Mean & 0.0013227 & 0.002444 & 0.0034944 & 29.90672 & 26.81733 & 25.18359 \\
\hline & Median & 0.0008851 & 0.0014436 & 0.0020217 & 33.2939 & 29.61395 & 27.81901 \\
\hline & Gaussian & 0.0028455 & 0.0045353 & 0.0059231 & 26.14482 & 24.12825 & 22.94312 \\
\hline \multirow{5}{*}{$\begin{array}{l}\text { Localvar } \\
\text { (intensity } \\
\text { map=0.02) }\end{array}$} & Minimum & 0.0413892 & 0.071041 & 0.0951859 & 13.85061 & 11.51017 & 10.24823 \\
\hline & Maximum & 0.0349108 & 0.05831 & 0.0764022 & 14.6108 & 12.44347 & 11.29206 \\
\hline & Mean & 0.0092104 & 0.0109173 & 0.0121194 & 20.38221 & 19.64448 & 19.1947 \\
\hline & Median & 0.0092329 & 0.0103057 & 0.0110184 & 20.37755 & 19.9036 & 19.61426 \\
\hline & Gaussian & 0.0114278 & 0.0131837 & 0.0145747 & 19.4598 & 18.85812 & 18.43545 \\
\hline
\end{tabular}




\section{KESIMPULAN DAN SARAN}

\subsection{Kesimpulan}

Berdasarkan hasil pengujian perbaikan citra dengan beberapa filter dengan menghitung nilai MSE dan PSNR, dapat disimpulkan sebagai berikut.

1. Filter mean merupakan filter yang paling baik digunakan untuk perbaikan kualitas citra dengan jenis noise gaussian, salt \& peppers dan speckle.

2. Filter median merupakan filter yang paling baik digunakan untuk perbaikan kualitas citra dengan jenis noise poisson dan localvar.

\subsection{Saran}

Kedepan perlu dilakukan penelitian lebih lanjut dengan berbagai data yang lebih banyak, dan dengan variasi jenis noise dan jenis filter yang lebih bervariasi. Variabel variabel lain, selain ukuran filter, yang mempengaruhi kualitas hasil filter perlu dibahas dan dilibatkan sebagai varibel penelitian lebih lanjut. Dengan demikian akan didapatkan sebuah formula yang bisa menyatakan secara pasti untuk setiap jenis noise, jenis filter apa yang paling cocok sebagai solusinya.

\section{DAFTAR PUSTAKA}

Dewi, A. K. A., \& Gunadi, I. G. A. (2018). Pengaruh Karakteristik Filter Spatial Terhadap Berbagai Jenis Noise Untuk Perbaikan Kualitas Citra Digital. In Seminar Nasional Pendidikan Teknik Informatika ke 9.

Kusumanto, R. D., Tompunu, A. N., \& Pambudi, S. (2011). Klasifikasi Warna Menggunakan Pengolahan Model Warna HSV Abstrak. Jurnal Ilmiah Teknik Elektro, 2(2), 83-87.

Patidar, P., Gupta, M., Srivastava, S., \& Nagawat, A. K. (2010). Image De-noising by Various Filters for Different Noise. International Journal of Computer Applications, 9(4), 45-50. http://doi.org/10.5120/1370-1846

Putra, D. (2010). Pengolahan citra digital. Penerbit Andi.

Rachmad, A. (2008). Pengolahan citra digital menggunakan teknik, 7-11.

Rohit Verma, M., \& Ali, J. (2013). A Comparative Study of Various Types of Image Noise and Efficient Noise Removal Techniques. International Journal of Advanced Research in Computer Science and Software Engineering, 3(10), 617 - 622. Retrieved from www.ijarcsse.com

Sutoyo, T., Mulyanto, E., Suhartono, V., Nurhayati, \& Wijanarto. (2009). Teori Pengolahan Citra Digital (Vol. 1). Yogyakarta: Andi. http://doi.org/10.1017/CBO9781107415324.004

Wang, Z., \& Li, Q. (2011). Information content weighting for perceptual image quality assessment. IEEE Transactions on Image Processing, 20(5), 1185-1198. http://doi.org/10.1109/TIP.2010.2092435

Wedianto, A., Sari, H. L., \& H, Y. S. (2016). Analisa Perbandingan Metode Filter Gaussian, Mean Dan Median Terhadap Reduksi Noise. Jurnal Media Infotama, 12(1), 21-30.

Yuwono, B. (2010). Image Smooting Menggunakan Mean Filtering, Median Filtering, Modus Filtering dan Gaussian Filtering. Pengolahan Citra Digital, 485323(0274), $65-75$. 